\title{
Focal Suppression of Epileptiform Activity in the Hippocampus by a High-Frequency Magnetic Field
}

Hui Ye

Loyola University Chicago, hye1@luc.edu

Vincent Chiun-Fan Chen

Loyola University Chicago, cchen17@luc.edu

Jessica Helon

Loyola University Chicago

Nicole Apostolopoulos

Loyola University Chicago

Follow this and additional works at: https://ecommons.luc.edu/biology_facpubs

Part of the Biology Commons

Author Manuscript

This is a pre-publication author manuscript of the final, published article.

\section{Recommended Citation}

Ye, Hui; Chen, Vincent Chiun-Fan; Helon, Jessica; and Apostolopoulos, Nicole. Focal Suppression of Epileptiform Activity in the Hippocampus by a High-Frequency Magnetic Field. Neuroscience, 432, : 1-14, 2020. Retrieved from Loyola eCommons, Biology: Faculty Publications and Other Works, http://dx.doi.org/ 10.1016/j.neuroscience.2020.02.018

This Article is brought to you for free and open access by the Faculty Publications and Other Works by Department at Loyola eCommons. It has been accepted for inclusion in Biology: Faculty Publications and Other Works by an authorized administrator of Loyola eCommons. For more information, please contact ecommons@luc.edu. c) (i) $\Theta$

This work is licensed under a Creative Commons Attribution-Noncommercial-No Derivative Works 3.0 License. (c) IBRO, 2020. 


\section{Focal suppression of epileptiform activity in the hippocampus by a high-frequency magnetic field}

Hui Ye ${ }^{1^{*}}$, Vincent C-F Chen², Jessica Helon ${ }^{1}$, Nicole Apostolopoulos ${ }^{1}$

1. Department of Biology, Loyola University Chicago

2. Engineering Science Program, Loyola University Chicago

${ }^{*}$ Correspondence:

Hui Ye, Ph.D.

Department of Biology

Loyola University Chicago

Quinlan Life Sciences Education and Research Center

1032 W. Sheridan Rd., Chicago, IL 60660

Tel (773) 508-2720

Hui Ye: hye1@luc.edu

\section{ABSTRACT}

Electric current has been used for epilepsy treatment by targeting specific neural circuitries. Despite its success, direct contact between the electrode and tissue could cause side effects including pain, inflammation, and adverse biological reactions. Magnetic stimulation overcomes these limitations by offering advantages over biocompatibility and operational feasibility. However, the underlying neurological mechanisms of its action are largely unknown. In this work, a magnetic generating system was assembled that included a miniature coil. The coil was positioned above the CA3 area of mouse hippocampal slices. Epileptiform activity (EFA) was induced with low $\mathrm{Mg}^{2+} /$ high $\mathrm{K}^{+}$perfusion or with $100 \mu \mathrm{M}$ 4-aminopyridine (4-AP). The miniature coil generated a sizable electric field that suppressed the local EFA in the hippocampus in the low- $\mathrm{Mg}^{2+} / \mathrm{high} \mathrm{K}^{+}$model. The inhibition effect was dependent on the frequency and duration of the magnetic stimulus, with high frequency being more effective in suppressing EFA. EFA suppression by the magnetic field was also observed in the 4-AP model, in a frequency and duration - dependent manner. The study provides a platform for further investigation of cellular and molecular mechanisms underlying epilepsy treatment with time varying magnetic fields.

Key Words: magnetic coil; induced electric field; hippocampus; epilepsy; electrophysiology 


\section{Introduction}

Epilepsy is one of the most prevalent neurological disorders affecting one out of every twenty-six people, with one-third of the patients remaining pharmacologically intractable over their seizures (Kwan and Brodie, 2000, Laxer et al., 2014). Therefore, resection and disconnection surgeries that are irreversible have to be considered, despite their association with neurological deficits such as memory loss, aphasia, and motor and visual impairments (Josephson et al., 2013).

Deep brain stimulation (DBS) has been used to suppress seizure activity in clinical settings by applying electrical stimulation to various parts of the brain, including centromedian (Velasco et al., 2000) and anterior nuclei (Fisher et al., 2010) of the thalamus, cerebellum (Cooper, 1973, Cooper et al., 1973), locus coeruleus (Faber and Vladyka, 1983), and hippocampus (Velasco et al., 2007, Smart et al., 2013, Thomas and Jobst, 2015). This reversible and adjustable alternative to resection has been proved to be successful in alleviating seizures in humans and has been used widely in clinical practices. Although effective, there are several limitations associated with DBS. First, maintaining response consistency over time with implanted electrodes has proved to be challenging. Second, inflammatory and immune reactions of the tissue occur in response to direct contact with the stimulation electrode, with restricted formation of glial scars surrounding the electrode (Polikov et al., 2005, Orlowski et al., 2017). The formation of glial scarring will alter or block the stimulation induced electric fields (Grill et al., 2009, Sillay et al., 2013). Due to the reduced effectiveness, biocompatibility of the implanted electrodes has become the primary concern in device design (Polikov et al., 2005).

An alternative method to generate electric current inside the brain is via electromagnetic induction of magnetic coils. Emerging evidence advocate the use of magnetic coil as an alternative treatment for epilepsy (Ye and Kaszuba, 2019). Recently, miniature-sized magnetic coils have been used to activate selected neuronal subpopulations while avoiding others (Bonmassar et al., 2012, Lee and Fried, 2014). In comparison to implanted electrodes, miniature coils offer advantages in preventing direct contact between the electrode and neural tissue, therefore eliminating numerous problems that may arise at the brain-electrode interface (Polikov et al., 2005, Cogan, 2008, Koivuniemi et al., 2011). These coils may be implanted for focal stimulation by being coated with insulated biocompatible materials. Such practices can increase the target tissue stimulation focality and avoid the adverse effects associated with implants (Saxena et al., 2013, Canales et al., 2015, Lee et al., 2016). However, it is unknown if the miniature coil could be effective in suppressing epileptic activity. 
Here, we designed a system that used a miniature coil to generate a sufficiently strong electric field. We recorded the in vitro epileptiform activity from the prepared hippocampal slices while applying the miniature coil stimulation to the CA3 area. We found that local EFA can be reliably inhibited by our miniature coils, especially at the higher frequency range of magnetic stimulation.

\section{Experimental Procedures}

\section{Animals}

All experimental protocols in this study were approved by the animal care committee at Loyola University Chicago in accordance with the policies established by Institutional Animal Care and Use Committee (IACUC). Care was taken to avoid unnecessary pain and suffering of the animals during the study. A total of $30 \mathrm{C} 57 \mathrm{BL} / 6 \mathrm{~J}$ mice of either gender (2-3 month of age, Charles River Laboratories, Wilmington, MA) were used in this study. Mice were kept in the Loyola University Chicago Animal Facility under continuous care by facility technicians.

\section{System/coil design}

We purchased commercial multilayer surface mount inductors $(100 \mathrm{nH}$, MLG1005SR10JTD25, TDK U.S.A. Corporation, Uniondale, NY). Each lead of the coil was soldered with a copper wire (magnetic wire 32-AWG, GC electronics, IL, L3-616). The coil was then covered with silicon glue (DAP All-Purpose 100\% Silicone Adhesive Sealant, DAP Products Inc., Baltimore, MD 21224) and allowed to cure in room temperature overnight before use. Silicon glue was chosen because of its very low electric conductivity, high dielectric strength, and excellent biocompatibility after in vivo implantation into animals (Ye et al., 2006b, a) .

The coil was positioned on the tip of a glass pipette (TW150F-4, WPS), with the two copper wires running through the inside of the pipette. The pipette was 4 inches long, and the inner diameter was $1.12 \mathrm{~mm}$, which secured the two wires inside the pipette. The pipette was then mounted on and secured to a micromanipulation for positioning the coil above the brain slices. The ends of the two wires were attached to the output of a $1000 \mathrm{~W}$ power amplifier with a bandwidth of 70 kHz (Pyramid PB 717X 2 channel, Pyramid Car Audio, Brooklyn, NY, 11204). The amplifier was powered by a Triple Channel DC Power Supply (2231A-30-3, Keithley). Voltage pulses (-10 V/10 V) were generated by an arbitrary function generator (AFG1022, Tektronix) and were delivered to the power amplifier (Fig. 1A). Since preliminary experiment with low frequency (less than $5 \mathrm{~Hz}$ ) did not produce any suppression effects of epileptiform activity, frequency ranging from $20 \mathrm{~Hz}$ to $400 \mathrm{~Hz}$ were tested. Pulses with width of $1 \mathrm{~ms}$ and duration of $10 \mathrm{~s}$ were generated. 
Longer durations of $20 \mathrm{~s}$ and $30 \mathrm{~s}$ were also tested whenever needed. The voltage across the coil during pulse train stimulation was measured for the computation of the induced electric field. Electric conductivity of the coil was confirmed by measuring its DC resistance (1.37 $\Omega)$. Potential leakage of the current from the coil was checked before and after each experiment. If presented, this current generated extremely large level of noise.

\section{Brain slice preparation}

Mice were anaesthetized with isoflurane and decapitated, and the brain was quickly removed and placed in ice-cold $\left(2-5^{\circ} \mathrm{C}\right)$ sucrose-based artificial cerebrospinal fluid (ACSF) for 3-5min. Sucrose-based ACSF contained (in mM): 210 sucrose, $26 \mathrm{NaHCO}_{3}, 2.5 \mathrm{KCl}, 1 \mathrm{CaCl}_{2}$, $4 \mathrm{MgCl}_{2}, 1.25 \mathrm{NaH}_{2} \mathrm{PO}_{4}$, and 10 glucose, and was continuously bubbled with $95 \% \mathrm{O}_{2}-5 \% \mathrm{CO}_{2}$. This high $\mathrm{Mg}^{2+}$ - low $\mathrm{Na}^{2+}$ - containing ACSF was used only during the tissue preparation to minimize neurotoxicity, mediated by $\mathrm{Na}^{+}$and neurotransmitter release (Jahromi et al., 2000). The cerebellum was removed and the brain was bisected along the midsagittal line. The superior cortex was removed and the dorsal cortex was cut parallel to the longitudinal axis. The brain tissue was then glued to an aluminum block with Cyanoacrylate glue with its ventral side up. The block was secured in a vibratome (Series 1000, Technical Products International, St. Louis, MO) so that the caudal end of the brain faced the blade. Slices $(400 \mu \mathrm{m})$ were cut, collected, and incubated in room temperature ACSF for at least $1 \mathrm{~h}$ before being transferred to a recording chamber. This normal ACSF contained (in $\mathrm{mM}$ ): $123 \mathrm{NaCl}, 26 \mathrm{NaHCO}_{3}, 2.5 \mathrm{KCl}, 1.8 \mathrm{CaCl}_{2}, 0.9 \mathrm{MgCl}_{2}$, $1.25 \mathrm{NaH}_{2} \mathrm{PO}_{4}$, and 10 glucose, and was continuously bubbled with $95 \% \mathrm{O}_{2}-5 \% \mathrm{CO}_{2}$.

\section{In vitro electrophysiology}

After 1 hour incubation, slices were moved to a recording chamber for extracellular field potential recording. Since cell viability has to be guaranteed through the time course of long-time recording, we have improved viability of the slice to more than 6 hours by implementing an in vitro slice recording membrane chamber (Hill and Greenfield, 2011) into our recording system. Slices were perfused with normal ACSF at a flow rate of 4-6 $\mathrm{ml} / \mathrm{min}$ at room temperature $\left(21^{\circ} \mathrm{C}\right)$. To precipitate EFA, the tissue was perfused with low $\mathrm{Mg}^{2+} /$ high $\mathrm{K}^{+}$ACSF containing the following (in $\mathrm{mM}$ ): $123 \mathrm{NaCl}, 5 \mathrm{KCl}, 1.5 \mathrm{CaCl}$, 0.25 MgSO4, $25 \mathrm{NaHCO}$, $1.2 \mathrm{NaH} 2 \mathrm{PO} 4$, and 15 glucose. For the 4-AP model of epilepsy, $100 \mu \mathrm{M}$ 4-aminopyridine was added into the normal ACSF during perfusion.

The mini coil was positioned above the CA3 stratum radiatum, with the winding of the coil parallel to the dendritic-somatic axis of the glutamatergic pyramidal neurons (Fig. 1B). No temperature change was observed in the recording chamber during our experiment. A recording 
borosilicate glass electrode, filled with $150 \mathrm{mM} \mathrm{NaCl}$, was placed in the CA3 stratum pyramidale to record EFA. The resistance of the electrode was around $10 \mathrm{M} \Omega$. In some experiments, the recording electrode was positioned in the CA1 area. Responses were filtered, amplified, and recorded with a PClamp 10 amplifier (Axon Instruments, Foster city, CA) and acquisition of data was performed using Clampex 10 (Axon Instruments) at a sampling rate of $25 \mathrm{kHz}$.

\section{Pharmacology}

The blocker of $\alpha$-amino-3-hydroxy-5-methyl-4-isoxalone/kainite (AMPA/KA) glutamate receptors, 6-cyano-7-nitroquinoxaline-2,3-dione (CNQX, $10 \mu \mathrm{M})$, and the blocker of N-methyl-Daspartate (NMDA) glutamate receptors, D-(-)-2-amino-5-phosphonopentanoic acid (D-APV, 10 $\mu \mathrm{M})$, were used to block glutamate receptors. All drugs were purchased from Sigma (Sigma, St. Louis, MO).

\section{Data analysis and statistics}

To improve the signal-to-noise ratio during magnetic stimulation, the raw recording was filtered by a band pass filter $(2.5 \mathrm{~Hz}-35 \mathrm{~Hz})$ to eliminate the high frequency noise picked up by the field recording electrode. After filtering, spontaneous spikes were counted with a threshold detecting program in Clampfit (Fig. 1C). To quantify the effects of magnetic stimulation, frequency (number of events/second) of the EFA was calculated (Chiang et al., 2014, Ledri et al., 2014). The spontaneous burst frequencies were compared in a $10 \mathrm{~s}$ period immediate before (Before group), during (During group), and after (After group) magnetic stimulation. Data was normalized to the mean frequency of the baseline data in each trial. Data from multiple stimulus trials and multiple slices was collected for each stimulation condition and pooled together for the analysis. Throughout the text, mean \pm standard error (SE) was reported. All data was verified for normal distribution and homogeneity of variance by KS normality and Levene test, respectively. Statistical significance was determined with one way repeated measures ANOVA followed by multiple comparisons with Bonferroni test for data with equal variance and normal distribution, and Garnes-Howell test for the data with no equal variance and/or no normal distribution using the Systat software (v. 13.1, Systat Software, Inc. San Jose, CA, USA). Effects were considered statistically significant at $p<0.05$. We acquired multiple slices from individual animals without within subject averaging in the final statistics (nested design). Ethically, this is a good method to reduce the number of animals in each experiment, however, this kind of data analysis, although commonly used in neuroscience, may reduce the statistical power (Aarts et al., 2014).

\section{Chemical dissolving of the inductor encapsulation}


To examine the detailed physical structure of the magnetic coil, the coil was placed into cell culture plate (24 well) and was treated with $1 \mathrm{ml}, 40 \%$ liquid hydrofluoric acid at room temperature for 48 hours. The acid was removed with a pipette and the coil was then gently washed three-times with deionized water. Thereafter, $10 \mathrm{~N} \mathrm{HCL}$ was added into the well for 1 hour and the acid was removed. The coil was again gently washed three times with deionized water. The coil was allowed to dry in room temperature (Fig. 2).

\section{Calculation of the induced electric field by the magnetic coil}

Magnetic field generated by a magnetic coil with radius $r$ was calculated by Faraday's law of induction, which made use of the magnetic flux $\Phi_{B}$ through a hypothetical surface $\Sigma$ whose boundary was a wire loop (Fig. 3). It stated that the EMF was given by the rate of change of the magnetic flux:

$$
\varepsilon=-\frac{d \phi_{B}}{d t}
$$

where $\varepsilon$ was the electromotive force $(E M F)$ and $\Phi_{\mathrm{B}}$ was the magnetic flux. Direction of the EMF followed left handed rule. It could also be written in an integral form by the Kelvin-Stokes

$$
\text { theorem. } \oint \vec{E} \cdot d \vec{l}=-\iint \frac{\partial \vec{B}}{\partial t} \cdot d \vec{A}
$$

Where $B$ was the magnetic field inside the coil. $E$ was the induced electric field. $d l$ was an infinitesimal vector element or the path element. $d A$ was an infinitesimal vector element of the area considered. If we were to consider the electric field inside the magnetic coil, at a point whose distance was $r$ from the coil center, by integrate

$$
2 \pi r E=-\pi r^{2} \frac{\partial B}{\partial t}
$$

we obtained the intensity of the induced electric field

$$
E=-\frac{r}{2} \frac{\partial B}{\partial t}(\mathrm{r}<\mathrm{R})
$$

Where $\mathrm{R}$ was the radius of the coil.

Outside the coil, 
7| P a g e

$$
2 \pi r E=-\pi R^{2} \frac{\partial B}{\partial t}
$$

The induced electric field was

$$
E=-\frac{R^{2}}{2 r} \frac{\partial B}{\partial t}(\mathrm{r}>\mathrm{R})
$$

Based on the "Ohm's law" for an inductor, we had

$$
v=L \frac{d I}{d t}(7)
$$

Where $v$ was the instantaneous voltage across the inductor, $L$ the inductance in Henrys, and $d l / d t$ the instantaneous current changes in A/s. For an inductor (coil) with a flowing current $(I)$ inside, the magnetic field was calculated by

$$
B=\mu_{0} \frac{N I}{l}
$$

Where $N$ was the loop number and / the length of the coil.

By combining (7) and (8), we had

$$
\frac{\partial B}{\partial t}=\frac{v \mu_{0} N}{L l}
$$

From (4) and (9), we had

$$
E=-\frac{r}{2} \frac{v \mu_{0} N}{L l} \quad(\mathrm{r}<\mathrm{R})
$$

From (6) and (9), we had

$$
E=-\frac{R^{2}}{2 r} \frac{v \mu_{0} N}{L l} \quad(\mathrm{r}>\mathrm{R})
$$

Distribution of the induced electric field generated by the miniature coil was plotted (Fig.4). 


\section{Results}

\section{Mini coil induced sizable electric field in the hippocampal slices}

Under time-varying magnetic stimulation, an electric field is induced by electromagnetic induction through the coil current. Previous study suggests that the intensity of an electric field plays a significant role in controlling neuronal activation and suppressing epileptiform activity in rat hippocampal slices (Gluckman et al., 1996). A $10 \mathrm{~V} / \mathrm{m}$ threshold for neuronal activation was reported by Chan and Nicholson (Chan and Nicholson, 1986). Fields at 10-20 V/m have been shown to modulate neurone-firing patterns of Purkinje and stellate cells in the isolated turtle cerebellum in vitro (Chan and Nicholson, 1986) or the guinea-pig hippocampus (Jefferys, 1981). Electric field suppression of epileptiform activity in rat hippocampal slices has been demonstrated for fields as low as 5-10 V/m (Gluckman et al., 1996).

We calculated the intensity of the electric field induced by the coil and found that the small size of the coil ensured a relatively large electric field to be generated locally around the coil. The output voltage across the coil was measured. We obtained coil parameters (TDK Corporation, MLG 1005 SR10JJD25) from the manufacture's data sheet. Length of the coil: $I=1$ $\mathrm{mm}$; Inductance: $\mathrm{L}=100 \mathrm{nH} ; \mu_{0}=4 \pi \times 10^{-7} \mathrm{H} / \mathrm{m}$; Structure of the inductor was exposed by chemically dissolving the outer layer. It contains 20 rectangular loops (1 mm length $X 0.5 \mathrm{~mm}$ width) (Fig. 2).

The intensity of the field inside the coil increased linearly with the distance to the center of the coil (Equ.10). Outside the coil, the field intensity decayed as a function of the distance between the targeted tissue and the center of the coil (Equ.11, Fig. 4A). When estimating the field intensity on the epileptic hippocampal tissue, two factors were considered. First, the coated material has an average thickness of about $200 \mu \mathrm{m}$. Second, the slicing process likely damaged cells on the top and bottom $50 \mu \mathrm{m}$ of the brain slices. As a result, these cells were likely not involved in generating epileptiform activity. Therefore, electric field that was 500-800 $\mu \mathrm{m}$ from the center of the coil was controlled the neural activity, which was within a range of $40-70 \mathrm{~V} / \mathrm{m}$ (Fig. 4B), strong enough to modulate cellular excitability and suppress epileptiform activity.

The miniature coil suppressed EFA in a low $-\mathrm{Mg}^{2+} / \mathrm{high}-\mathrm{K}^{+}$model and demonstrated frequency and duration dependencies

To elicit EFA, ACSF with low- $\mathrm{Mg}^{2+} / \mathrm{high}-\mathrm{K}^{+}$concentration was used to continuously perfuse the brain slices. This manipulation induced stable bursting, epileptiform activity for up to several hours, as seen in other studies (Lian et al., 2003, Isaev et al., 2005, Kang et al., 2010). 
These EFAs can be recorded in several anatomic locations such as CA3, CA2, and CA1 areas. The EFA could be completely eliminated by the ionotropic glutamate receptor antagonists CNQX $(10 \mu \mathrm{M})$ and AP5 $(50 \mu \mathrm{M})$, indicating that they were glutamate-mediated events (data not shown). We focused on the CA3 area of the hippocampus, a critical region for the initiation of EFA (Dzhala and Staley, 2003, Derchansky et al., 2006, Zhang et al., 2012). Previous studies using direct electric stimulation have indicated that EFA suppression was most effective when electric current flows through the dendritic-somatic axis of the glutamatergic pyramidal neurons (Jefferys, 1981, Gluckman et al., 1996). We therefore positioned the coil in an orientation so that the magneticallyinduced electric field can meet this requirement for the CA3 pyramidal neurons (Fig. 1B).

Previous work with electric (Lian et al., 2003) or optical (Chiang et al., 2014) stimulation suggested that the efficacy of in vitro EFA suppression was dependent on the stimulus frequency. Therefore, we systematically tested the pulse frequency on EFA inhibition by the miniature magnetic coil using $20 \mathrm{~Hz}, 50 \mathrm{~Hz}, 100 \mathrm{~Hz}, 200 \mathrm{~Hz}$, and $400 \mathrm{~Hz}$ (pulse width was 1 ms and duration was $10 \mathrm{~s})$, and received the following results.

$20 \mathrm{~Hz}$ stimulus (Fig. 5A) caused slight decrease of EFA spiking frequency (to $87.5 \% \pm$ $9.7 \%$ of the base line). However, when EFA frequencies before, during, and after stimulus were compared, one way repeated measures ANOVA revealed that $20 \mathrm{~Hz}$ stimulation had no significant effect $\left(F_{(2,30)}=1.6, p=0.219\right) .50 \mathrm{~Hz}$ stimulus (Fig. 5B) significantly altered the EFA frequency during stimulation $\left(F_{(2,15)}=5.7, p<0.05\right)$. The During group showed significantly lower frequency than the Before group $(p<0.05)$, whereas Before and After groups were not significantly different from each other ( $p>0.05$ ), suggesting a full recovery of network activity post-stimulus. $100 \mathrm{~Hz}$ stimulus (Fig. 5C) provided further alteration of the $\operatorname{EFA}\left(F_{(2,12)}=8.3, p<0.01\right)$. Both Before and After groups were different from the During group $(p<0.05)$, whereas Before and After groups were not significantly different from each other $(p>0.05)$, suggesting a full recovery of network activity post-stimulus. $200 \mathrm{~Hz}$ stimulus (Fig. 5D) had a significant effect in altering EFA activity during stimulation $\left(F_{(2,24)}=38.2, p<0.001\right)$. Both the Before and After groups were different from the During group $(p<0.001)$, whereas Before and After groups were not significantly different from each other $(p>0.05)$. However, the EFA frequency in the After group was slightly lower after a 10 $\mathrm{s}$ post-stimulus period.

Complete blockage of EFA in CA3 was easily achieved with $400 \mathrm{~Hz}$ pulses $(1 \mathrm{~ms}, 10 \mathrm{~s}$ duration) (Fig. 5E). One-way repeated measures ANOVA on the three groups (Before, During and After) revealed that $400 \mathrm{~Hz}$ magnetic field stimulation had a significant effect $\left(F_{(2,12)}=242.7\right.$, $p<0.001)$. Each two of these three groups were significantly different $(p<0.001) .400 \mathrm{~Hz}$ magnetic 
stimulus temporally enhanced the EFA during magnetic stimulation. EFA was completely suppressed by the $10 \mathrm{~s}$ stimulation, for more than 1 minute $(82.1 \pm 9.6 \mathrm{~s} ; \mathrm{n}=5)$ post-stimulus.

In summary, there was a dynamic EFA change associated with the increase in the stimulus frequency during magnetic stimulation. The magnetic field partially suppressed EFA during stimulation when the field frequency was lower than $200 \mathrm{~Hz}$. Higher frequency magnetic field $(>200 \mathrm{~Hz}$ ) temporally intensified the EFA during stimulation but alleviated or completely suppressed the EFA post-stimulus. To illustrate this pattern change, we analyzed all the data with frequency as a single factor. One-way repeated measures ANOVA revealed that field frequency was a significant factor in altering the EFA during stimulation $\left(F_{(4,31)}=43.7, p<0.001\right)$ and in suppressing post-stimulus EFA $\left(F_{(4,31)}=17.0\right.$, $\left.p<0.001\right)$ (Figs. $5 F$ and $\left.5 G\right)$.

To investigate the threshold of stimulus duration that could ensure complete EFA suppression, we systematically applied $400 \mathrm{~Hz}$ magnetic stimulus while varying the stimulus duration between 1 to $10 \mathrm{~s}$ to the brain slice (Fig. 6). The minimal duration for causing complete suppression of post-stimulus EFA was $4 \mathrm{~s}$. When stimulation duration was $>4 \mathrm{~s}$, there was a linear relationship between the duration of complete EFA suppression and the duration of stimulation $\left(R^{2}=0.988, p<0.001\right)$.

Prolonged magnetic stimulation can produce extra suppressive effects on the EFA. We tested this possibility for $200 \mathrm{~Hz}$ stimulus, a frequency that was incapable of producing a complete EFA suppression, if stimulus duration was short (10 s, Fig. 5D). Indeed, when we doubled or tripled the stimulus duration (to $20 \mathrm{~s}$ or $30 \mathrm{~s}$ ), $200 \mathrm{~Hz}$ stimulus completely suppressed EFA poststimulus ( $n=3$, Fig. 7). With the prolonged stimulation, $200 \mathrm{~Hz}$ stimulus was able to eliminate EFA for about 30 second post-stimulus.

\section{Suppression of EFA in CA3 was a localized phenomenon}

Intensity of the induced electric field decreased dramatically in the area farther away from the coil (Fig. 4). Therefore, we hypothesized that the inhibitory effect of the coil was limited to the local area (CA3). We recorded EFA from the CA1 area when the CA3 area was stimulated (Fig. 8) with $400 \mathrm{~Hz}$ (1 ms width and $10 \mathrm{~s}$ duration) pulses and failed to observe EFA suppression in CA1 $\left(F_{(2,21)}=0.389 . p=0.682\right)$. Further increase of stimulation duration in CA3 to 30 seconds was not effective in EFA suppression in CA1 (data not shown). We concluded that the miniature coil only suppressed local EFA.

The miniature coil suppressed EFA in the 4-AP model and also demonstrated frequency and duration dependencies 
EFA suppression in CA3 by the miniature coil was also observed in the 4-AP model of epilepsy. Hippocampal slices were perfused with ACSF that contained $100 \mu \mathrm{M}$ 4-aminopyridine (4-AP), which generated EFA featured as spikes of constant frequency (2-4 spikes/10 seconds) (Chiang et al., 2014, Ledri et al., 2014). The 10 s, $20 \mathrm{~Hz}$ magnetic field induced a significant EFA suppression $\left(F_{(2,15)}=26.9, p<0.01\right)$ during stimulation (Fig. 9A). The $50 \mathrm{~Hz}(n=5)$ or $200 \mathrm{~Hz}(n=4)$ stimulation completely suppressed the EFA in CA3. Stimulation with longer duration caused prolonged EFA suppression. Figs. 9B and 9C illustrate two examples in which $50 \mathrm{~Hz}$ or $200 \mathrm{~Hz}$ stimulation were delivered to the hippocampal slices. Complete suppression was observed in both short (10 s) and long (30 s) stimulation episodes. Unlike what occurred in the low- $\mathrm{Mg}^{2+} / \mathrm{high}^{-\mathrm{K}^{+}}$ model (in which post-stimulus EFA was inhibited), EFA in the 4-AP model resumed to its normal frequency once the magnetic stimulation was terminated. Figs $9 \mathrm{D}$ and $9 \mathrm{E}$ summarize the EFA changes under different stimulation frequency. Overall, field frequency was a significant factor for EFA suppression during stimulation $\left(\mathrm{F}_{(2,12)}=32.4, \mathrm{p}<0.001\right)$.

\section{Discussion}

Despite the great potential for magnetic treatment of epilepsy, laboratory research that focuses on the mechanisms of magnetic field stimulation at the molecular, cellular, and network levels are of great value in facilitating this translation. With a mini-coil that delivered magnetic fields, we observed partial or complete focal EFA inhibition in two different in vitro models of epilepsy in the hippocampus. The work composes an important step towards in-depth cellular/molecular studies on the mechanisms of magnetic control over abnormal excitability in epilepsy. The miniature coil has a dimension of $1 \mathrm{~mm} \times 0.5 \mathrm{~mm} \times 0.5 \mathrm{~mm}$. This small dimension is comparable to the cylinder shaped electrode $(1.5 \mathrm{~mm}$ in height and $1.27 \mathrm{~mm}$ in diameter $)$ in the Medtronic 3387/3389 quadripolar DBS electrode (Medtronic Inc, Minneapolis, MN). Covered by biocompatible material, the miniature coil could potentially be implanted into the epileptic foci as a valuable alternative to the existing electrode-based method used in the treatment of epilepsy.

\section{Both high frequency and low frequency have been used for seizure suppression with electric stimulation}

A large range of frequency spectrum has been explored in electric stimulation for seizure suppression, including high frequency stimulation (HFS) and low frequency stimulation (LFS). Deep brain stimulation with high frequency stimulus has targeted gray matter structures. Although the optimal stimulation parameters are undetermined (Saillet et al., 2009), clinical and experimental studies suggest that HFS produces a palliative effect on seizures. For example, 60 $\mathrm{Hz}$ stimulation decreased the primary and secondary generalized tonic-clonic seizures in the 
thalamic centromedian nucleus in patients with medically intractable epilepsy (Velasco et al., 2000). In patients with non-lesional temporal lobe epilepsy, HFS (130 Hz)stimulation caused a reduction of the interictal discharges and absence of seizures (Boex et al., 2007). Low frequency electrical stimulation (LFS) is also a potential therapeutic method for epilepsy treatment. LFS was applied to reduce seizures in patients with epileptic disorders but refractory to conventional antiepileptic treatment, including temporal lobe epilepsy (Theodore and Fisher, 2004, Yamamoto et al., 2006). It has also been reported that LFS on a fiber track (fornix) reduced epileptiform discharges and seizures in patients with intractable mesial temporal lobe epilepsy (Koubeissi et al., 2013).

Animal models of epilepsy were used to test the parameters of stimulations and reveal neurological mechanisms of stimulation. In pentylenetetrazole (PTZ)-induced seizures, $100 \mathrm{~Hz}$ electric pulses were anti-epileptogenic in stimulating thalamic reticular nucleus (Pantoja-Jimenez et al., 2014) and anterior thalamic nuclear complex (AN) (Mirski et al., 1997). In the kindling model of rats, $50 \mathrm{~Hz}$ stimulation in thalamic reticular nucleus caused suppression of limbic motor seizures (Nanobashvili et al., 2003). Animal research also showed positive anti-epileptic effects of LFS. In hippocampus - kindling rats, LFS in the hippocampus showed improved long-term spatial learning and memory (Esmaeilpour et al., 2017). In amygdala-kindled rats, LFS combined with sub-threshold dosages of anticonvulsant drug phenobarbital significantly reduced seizures (Asgari et al., 2014). Targeting on the fiber-track, such as corpus callosum, LFS suppressed seizures in a rat model of focal cortical seizures (Couturier and Durand, 2018). It has further been reported that LFS on the hippocampal commissure reduced seizures in a rat model of chronic temporal lobe epilepsy (Rashid et al., 2012).

Brain slices were used to further investigate the cellular/ionic mechanism of electric stimulation on seizure suppression. For HFS, $50 \mathrm{~Hz}$ pulses suppressed EFA in several in vitro models of epilepsy (low $\mathrm{Ca}^{2+}$, picrotoxin, and high $\mathrm{K}^{+}$) (Lian et al., 2003). Sinusoidal high frequency $(20-50 \mathrm{~Hz})$ electric fields across rat hippocampal slices were found to suppress zero$\mathrm{Ca}^{2+}$, low-Ca ${ }^{2+}$, picrotoxin, and high- $\mathrm{K}^{+}$epileptiform activity throughout the duration of the stimulus and for up to several minutes following the stimulus. EFA suppression was also found at even higher frequencies (<500 Hz) (Bikson et al., 2001). For LFS, 0.1 or $1 \mathrm{~Hz} L F S$ in the lateral nucleus of the amygdala abolished the ictal-like epileptiform discharges induced by 4-AP in the perirhinal cortex in the rate brain slices preparations. These effects were mediated by $G_{A B A}$ receptors (Kano et al., 2015). LFS on the commissural fibre tract reduces bilateral hippocampal epileptic activity, due to the stimulation-induced long-lasting hyperpolarizing, which is mediated through $\mathrm{GABA}_{\mathrm{B}}$ receptor activity (Toprani and Durand, 2013). The $1 \mathrm{~Hz}$ LFS on the Schaffer collaterals 
prevented high- $\mathrm{K}^{+}$- induced neuronal hyper-excitability in the hippocampal neurons (Ghasemi et al., 2018).

\section{Implementation of clinically unattainable high frequency magnetic stimulation}

In contrast to the successful seizure suppression with both high frequency and low frequency electric stimulation, epilepsy treatment with magnetic stimulation are mainly using low frequency stimulation.

Starting from the 1990s, magnetic fields have been applied in epilepsy treatment (Anninos et al., 1991, Anninos et al., 1999) and have shown some anticonvulsant effects in epileptic patients (Anninos et al., 1999) (Sandyk and Anninos, 1992). Case reports demonstrated reduction of seizure frequency and/or epileptic discharges after repetitive transcranial magnetic stimulation (rTMS) (Menkes and Gruenthal, 2000) (Brasil-Neto et al., 2004) (Kinoshita et al., 2005) (Liu et al., 2013) (Fregni et al., 2006) (Sun et al., 2012). The rTMS studies use relative low frequency $(<1$ $\mathrm{Hz}$ ) (Rossi et al., 2009) (Muller et al., 2014). For example, $0.5 \mathrm{~Hz}$ slow-frequency rTMS led to a $70 \%$ reduction in the frequency of seizures in a patient with medically refractory partial seizures (Menkes and Gruenthal, 2000). The $0.3 \mathrm{~Hz}$ rTMS decreased mean daily number of seizures in patients with intractable epilepsy by $22.8 \%$ (Brasil-Neto et al., 2004). These low frequency rTMS protocols also showed their anti-epileptic effects in mice work, with picrotoxin-induced (Kistsen et al., 2016) or bicuculline-induced convulsions (Sung et al., 2003).

Apparently, the frequency band of interests in those clinical applications was much lower than our in vitro implementation. This was partially due to the technical difficulties encountered in delivering larger currents to the coil at higher frequencies in rTMS practice (much higher impedance, much higher energy-storage requirement, and much severe cooling issues) and the concern that high frequency stimulation had the tendency of inducing seizures (Rossi et al., 2009). However, anti-epileptic effects of high frequency magnetic stimuli started to appear in some animal studies. Short duration, high frequency $(20 \mathrm{~Hz})$ rTMS train has long-term anticonvulsant effects (Ebert and Ziemann, 1999). Animal work also shows that at high frequency, rTMS could decrease epileptic spike frequency acutely (Gersner et al., 2016), which was supported by this study. Further studies are needed to explore the possibility of adapting such high frequency spectrum into future rTMS treatment of epilepsy.

\section{Possible mechanisms of action of high frequency magnetic field on EFA suppression}

In this study, we reported that magnetic stimulation at high frequencies can generate reliable focal EFA suppression. In the low- $\mathrm{Mg}^{2+} / \mathrm{high}^{-\mathrm{K}^{+}}$model, EFA was reduced during 20-100 $\mathrm{Hz}$ stimulation. For frequency at $200 \mathrm{~Hz}$, the field reduced EFA post-stimulus. Higher frequency 
$(400 \mathrm{~Hz})$ caused complete suppression of EFA for up to 90 seconds, nine times of the stimulation duration. Longer duration of coil stimulation would enhance the suppressive effects of the magnetic field at both $200 \mathrm{~Hz}$ and $400 \mathrm{~Hz}$. For the 4-AP model, magnetic stimulation at $50 \mathrm{~Hz}$ or higher was sufficient for complete EFA suppression, even for stimulus with long durations (up to 30 second). The inhibiting effects were local to the stimulation site, due to a quick decay of coilinduced electric field around the coil.

Similarity between the electrode-produced HFS in EFA suppression, and our coilproduced results at high frequency range, leads to the speculation that the neurological mechanisms behind the two stimuli share certain similarity. There are several possible biophysics and neurological mechanisms for EFA suppression by the time-varying magnetic field and the induced secondary electric field. First, the magnetic stimulation, via its induced electric field, could have caused excessive $\mathrm{K}^{+}$release, generating the associated depolarization block of epileptic neurons (Bikson et al., 2001, Lian et al., 2003).

Second, magnetic field could alter synaptic transmission via its induced electric field, including long- and short-term modulations. Short-term depression of synaptic transmission was observed during high frequency electric stimulation in the globus pallidus in rats (Rav-Acha et al., 2005) and in primates (Erez et al., 2009). Depression of synaptic transmission by HFS could be due to the fact that HFS-induced release of inhibitory GABA molecules is more prominent than the excitatory neurotransmitter (Feuerstein et al., 2011). Alternatively, it could be due to axonal and/or synaptic failure, which suppress the synaptic transfer of firing rate oscillations, synchrony, and rate-coded information during high frequency stimulation (Rosenbaum et al., 2014). Magnetic field could also modulates long term potential (LTP) induction in the hippocampal area of rats (Komaki et al., 2014, Dong et al., 2018), probably due to a NMDAR-dependent mechanism (Tokay et al., 2009).

Third, neurons affect each other via extracellular electric fields and ephaptic interactions. As extracellular fields and ephaptic interactions respectively play significant roles in recruitment/synchronization of neuronal activity (Mann-Metzer and Yarom, 2000) and nonsynaptic epileptogenesis (Haas and Jefferys, 1984) (Richardson and O'Reilly, 1995) (Bawin et al., 1986) (Jefferys, 1981) (Konnerth et al., 1986) (Snow and Dudek, 1984). It is possible that magnetically-induced electric fields will interrupt this "coupling" and desynchronize the neuronal firing of an epileptic circuit (Ye and Steiger, 2015). This possibility could be tested in the future by using in vitro models that are elicited by zero $\mathrm{Ca}^{2+}$ (Bikson et al., 1999), which presumably lack 
synaptic transmission capabilities but with field coupling still available. Methods established in this brain slice work could lead to in-depth cellular /molecular studies on these mechanisms.

\section{Potential long-term effects of magnetic stimulation}

We observed acute inhibition of epileptic form activity by the magnetic stimulation in this in vitro study using brain slices. We, however, cannot exclude the possibility that miniature coil stimulation could cause long-term effects in epileptic suppression, as those observed in the clinical cases during DBS treatment of epilepsy (Velasco et al., 2007). Electric stimulation could introduce modulation of neurotrophic factors at the site of stimulation (Ho et al., 2014). It could also introduce genetic modulation locally and in the regions receiving projects from the area undergoing stimulation (Ewing et al., 2013). Similarly, evidence of long-term effects of magnetic stimulation is abundant, including its enhancing effect on adult neural stem and progenitor cell proliferation (Cullen and Young, 2016). Further in vivo work, using chronical implantation of miniature coil (covered with biocompatible materials) into the animals, will ultimately reveal this possibility.

Acknowledgement: Jessica Helon and Nicole Apostolopoulos are supported by the LUROP research fellowship from Loyola University Chicago.

Funding: This research did not receive any specific grant funding from agencies in the public, commercial, or not-for-profit sectors.

Declarations of interest: None

\section{Figure legends}

Figure 1. A. Magnetic field generator, which included a signal generator, a power amplifier and a coil held by a glass tube. B. Orientation of the magnetic coil and the hippocampal slice. The coil was positioned in the CA3 area, with the winding of the coil parallel to the dendritic-somatic axis of the CA3 pyramidal cells. Recording electrode was inserted into the CA3 stratum pyramidale. C. Filtering method for the detection of the epileptiform activity in the low $\mathrm{Mg}^{2+} / \mathrm{high}^{+}$model. 1 . Epileptiform activity recorded from the CA3 area, which was stimulated for $10 \mathrm{~s}$ by a $200 \mathrm{~Hz}$ magnetic field. 2. Filtered data by a band pass filter showed an improved signal-noise ratio. 3 . Spike detection based on the threshold method.

Figure 2. Size and structure of the magnetic coil. A. Image of a miniature coil used in the study relative to a pencil point. $B$. The outer cover of the coil was chemically dissolved to reveal the 
structure of the solenoid. The coil consists of 20 loops of wire (approximately $0.1 \mathrm{~mm}$ in width) that is $1 \mathrm{~mm} \times 0.5 \mathrm{~mm}$ rectangular in shape.

Figure 3. Magnetic flux $(B)$ generated by the current $(I)$ inside a modeled coil with a radius $R$. The induced electric field was $E$.

Figure 4. Intensity of the induced electric field inside and outside of the modeled mini-coil. A. Color map plot for the field intensity and its distribution around the coil (represented by the black ring). B. Relationship between field intensity and the distance from the coil center. Area of the locations of the brain slice was illustrated.

Figure 5. Suppression of epileptiform activity (EFA) by the high-frequency magnetic field in the hippocampus CA3 area in the low Mg²+/high-K+ model. A. $20 \mathrm{~Hz}$. B. $50 \mathrm{~Hz}$. C. $100 \mathrm{~Hz}$. D. $200 \mathrm{~Hz}$. E. $400 \mathrm{~Hz}$ magnetic stimulation (1ms pulse width, 10 second duration). Red bars represented the time of magnetic stimulation. Blue bars represented the complete suppression of the EFA. F. Frequency-dependency of EFA suppression during magnetic stimulation. G. Frequencydependency of EFA suppression post-stimulation. Asterisks represented the statistical significance when compared with baseline frequency. ${ }^{*} p<0.05 ;{ }^{* *} p<0.01 ;{ }^{* * *} p<0.001$.

Figure 6. Threshold of stimulation duration that ensured complete EFA suppression at $400 \mathrm{~Hz}$. A. Magnetic stimulus with a duration $1 \mathrm{~s}$ to $10 \mathrm{~s}$ was applied, with $1 \mathrm{~s}$ as increment. B. Expanded traces for $1 \mathrm{~s}, 7 \mathrm{~s}$, and $10 \mathrm{~s}$ stimulation. Blue bars represented the complete suppression of the EFA. C. Relationship between the stimulus duration and the duration of the complete EFA inhibition. A minimal of $4 \mathrm{~s}$ was needed for $400 \mathrm{~Hz}$ stimulation to cause complete suppression post-stimulus. Linear regression showed duration of complete suppression (s) $=-78.3+18.95 X$ stimulation duration (s).

Figure 7. Prolonged magnetic stimulation produced extra suppression effects on EFA. A prolonged magnetic stimulation (30 s) at $200 \mathrm{~Hz}$ led to complete inhibition post-stimulus, while shorter stimulation (10 s) at the same frequency only provided partial inhibition post-stimulus. Red bars represented the time of magnetic stimulation. Blue bars represented the complete suppression of the EFA.

Figure 8. EFA suppression by the magnetic coil was a local phenomenon and was not observed in the CA1 area. A. Illustration of coil position in CA3, and electrode position in CA1 pyramidal. B. 
Raw data for $400 \mathrm{~Hz}, 1 \mathrm{~ms}$, and $10 \mathrm{~s}$ stimulation. Red bars represented the time of magnetic stimulation. C. Statistic summary of the changes in the EFA frequency before, during, and after magnetic stimulation.

Figure 9. Suppression of EFA by a high-frequency magnetic field in the hippocampus in the 4-AP model $(100 \mu \mathrm{M})$. A. $20 \mathrm{~Hz}$ magnetic field partially suppressed EFA. B. $50 \mathrm{~Hz}$ magnetic field completely suppressed EFA during stimulation. C. $200 \mathrm{~Hz}$ magnetic field completely suppressed EFA. Longer (30s) stimulation caused prolonged suppression. Red bars represented the time of magnetic stimulation. $D$ and $E$. Summary of frequency-dependency of the magnetic suppression on 4-AP induced EFA during stimulation and post-stimulation. Asterisks represent the statistical significance when compared with baseline frequency. ${ }^{*} p<0.05 ;{ }^{* *} p<0.01 ;{ }^{* * *} p<0.001$.

Aarts E, Verhage M, Veenvliet JV, Dolan CV, van der Sluis S (2014) A solution to dependency: using multilevel analysis to accommodate nested data. Nature neuroscience 17:491-496.

Anninos PA, Tsagas N, Jacobson JI, Kotini A (1999) The biological effects of magnetic stimulation in epileptic patients. Panminerva medica 41:207-215.

Anninos PA, Tsagas N, Sandyk R, Derpapas K (1991) Magnetic stimulation in the treatment of partial seizures. Int J Neurosci 60:141-171.

Asgari A, Semnanian S, Atapour N, Shojaei A, Moradi H, Mirnajafi-Zadeh J (2014) Combined subthreshold dosages of phenobarbital and low-frequency stimulation effectively reduce seizures in amygdala-kindled rats. Neurological sciences : official journal of the Italian Neurological Society and of the Italian Society of Clinical Neurophysiology 35:1255-1260.

Bawin SM, Abu-Assal ML, Sheppard AR, Mahoney MD, Adey WR (1986) Long-term effects of sinusoidal extracellular electric fields in penicillin-treated rat hippocampal slices. Brain research 399:194199.

Bikson M, Ghai RS, Baraban SC, Durand DM (1999) Modulation of burst frequency, duration, and amplitude in the zero-Ca(2+) model of epileptiform activity. Journal of neurophysiology 82:22622270.

Bikson M, Lian J, Hahn PJ, Stacey WC, Sciortino C, Durand DM (2001) Suppression of epileptiform activity by high frequency sinusoidal fields in rat hippocampal slices. The Journal of physiology 531:181191.

Boex C, Vulliemoz S, Spinelli L, Pollo C, Seeck M (2007) High and low frequency electrical stimulation in non-lesional temporal lobe epilepsy. Seizure 16:664-669.

Bonmassar G, Lee SW, Freeman DK, Polasek M, Fried SI, Gale JT (2012) Microscopic magnetic stimulation of neural tissue. Nature communications 3:921.

Brasil-Neto JP, de Araujo DP, Teixeira WA, Araujo VP, Boechat-Barros R (2004) Experimental therapy of epilepsy with transcranial magnetic stimulation: lack of additional benefit with prolonged treatment. Arq Neuropsiquiatr 62:21-25. 
Canales A, Jia X, Froriep UP, Koppes RA, Tringides CM, Selvidge J, Lu C, Hou C, Wei L, Fink Y, Anikeeva P (2015) Multifunctional fibers for simultaneous optical, electrical and chemical interrogation of neural circuits in vivo. Nat Biotechnol 33:277-284.

Chan CY, Nicholson C (1986) Modulation by applied electric fields of Purkinje and stellate cell activity in the isolated turtle cerebellum. The Journal of physiology 371:89-114.

Chiang CC, Ladas TP, Gonzalez-Reyes LE, Durand DM (2014) Seizure suppression by high frequency optogenetic stimulation using in vitro and in vivo animal models of epilepsy. Brain stimulation 7:890-899.

Cogan SF (2008) Neural stimulation and recording electrodes. Annual review of biomedical engineering 10:275-309.

Cooper IS (1973) Effect of stimulation of posterior cerebellum on neurological disease. Lancet 1:1321.

Cooper IS, Crighel E, Amin I (1973) Clinical and physiological effects of stimulation of the paleocerebellum in humans. Journal of the American Geriatrics Society 21:40-43.

Couturier NH, Durand DM (2018) Corpus callosum low-frequency stimulation suppresses seizures in an acute rat model of focal cortical seizures. Epilepsia 59:2219-2230.

Cullen CL, Young KM (2016) How Does Transcranial Magnetic Stimulation Influence Glial Cells in the Central Nervous System? Frontiers in neural circuits 10:26.

Derchansky M, Rokni D, Rick JT, Wennberg R, Bardakjian BL, Zhang L, Yarom Y, Carlen PL (2006) Bidirectional multisite seizure propagation in the intact isolated hippocampus: the multifocality of the seizure "focus". Neurobiology of disease 23:312-328.

Dong L, Zheng Y, Li ZY, Li G, Lin L (2018) Modulating effects of on-line low frequency electromagnetic fields on hippocampal long-term potentiation in young male Sprague-Dawley rat. Journal of neuroscience research.

Dzhala VI, Staley KJ (2003) Transition from interictal to ictal activity in limbic networks in vitro. The Journal of neuroscience : the official journal of the Society for Neuroscience 23:7873-7880.

Ebert U, Ziemann U (1999) Altered seizure susceptibility after high-frequency transcranial magnetic stimulation in rats. Neuroscience letters 273:155-158.

Erez Y, Czitron H, McCairn K, Belelovsky K, Bar-Gad I (2009) Short-term depression of synaptic transmission during stimulation in the globus pallidus of 1-methyl-4-phenyl-1,2,3,6tetrahydropyridine-treated primates. The Journal of neuroscience : the official journal of the Society for Neuroscience 29:7797-7802.

Esmaeilpour K, Sheibani V, Shabani M, Mirnajafi-Zadeh J (2017) Effect of low frequency electrical stimulation on seizure-induced short- and long-term impairments in learning and memory in rats. Physiology \& behavior 168:112-121.

Ewing SG, Porr B, Pratt JA (2013) Deep brain stimulation of the mediodorsal thalamic nucleus yields increases in the expression of zif-268 but not c-fos in the frontal cortex. Journal of chemical neuroanatomy 52:20-24.

Faber J, Vladyka V (1983) Antiepileptic effect of electric stimulation of the locus coeruleus in man. Activitas nervosa superior 25:304-308.

Feuerstein TJ, Kammerer M, Lucking CH, Moser A (2011) Selective GABA release as a mechanistic basis of high-frequency stimulation used for the treatment of neuropsychiatric diseases. Naunyn Schmiedebergs Arch Pharmacol 384:1-20.

Fisher R, Salanova V, Witt T, Worth R, Henry T, Gross R, Oommen K, Osorio I, Nazzaro J, Labar D, Kaplitt M, Sperling M, Sandok E, Neal J, Handforth A, Stern J, DeSalles A, Chung S, Shetter A, Bergen D, Bakay R, Henderson J, French J, Baltuch G, Rosenfeld W, Youkilis A, Marks W, Garcia P, Barbaro N, Fountain N, Bazil C, Goodman R, McKhann G, Babu Krishnamurthy K, Papavassiliou S, Epstein C, Pollard J, Tonder L, Grebin J, Coffey R, Graves N, Group SS (2010) Electrical stimulation of the anterior nucleus of thalamus for treatment of refractory epilepsy. Epilepsia 51:899-908. 
Fregni F, Otachi PT, Do Valle A, Boggio PS, Thut G, Rigonatti SP, Pascual-Leone A, Valente KD (2006) A randomized clinical trial of repetitive transcranial magnetic stimulation in patients with refractory epilepsy. Ann Neurol 60:447-455.

Gersner R, Dhamne SC, Zangen A, Pascual-Leone A, Rotenberg A (2016) Bursts of high-frequency repetitive transcranial magnetic stimulation (rTMS), together with lorazepam, suppress seizures in a rat kainate status epilepticus model. Epilepsy \& behavior : E\&B 62:136-139.

Ghasemi Z, Naderi N, Shojaei A, Raoufy MR, Ahmadirad N, Mirnajafi-Zadeh J (2018) Effect of LowFrequency Electrical Stimulation on the High-K(+)-Induced Neuronal Hyperexcitability in Rat Hippocampal Slices. Neuroscience 369:87-96.

Gluckman BJ, Neel EJ, Netoff TI, Ditto WL, Spano ML, Schiff SJ (1996) Electric field suppression of epileptiform activity in hippocampal slices. Journal of neurophysiology 76:4202-4205.

Grill WM, Norman SE, Bellamkonda RV (2009) Implanted neural interfaces: biochallenges and engineered solutions. Annual review of biomedical engineering 11:1-24.

Haas HL, Jefferys JG (1984) Low-calcium field burst discharges of CA1 pyramidal neurones in rat hippocampal slices. The Journal of physiology 354:185-201.

Hill MR, Greenfield SA (2011) The membrane chamber: a new type of in vitro recording chamber. Journal of neuroscience methods 195:15-23.

Ho DX, Tan YC, Tan J, Too HP, Ng WH (2014) High-frequency stimulation of the globus pallidus interna nucleus modulates GFRalpha1 gene expression in the basal ganglia. Journal of clinical neuroscience : official journal of the Neurosurgical Society of Australasia 21:657-660.

Isaev D, Isaeva E, Khazipov R, Holmes GL (2005) Anticonvulsant action of GABA in the high potassiumlow magnesium model of ictogenesis in the neonatal rat hippocampus in vivo and in vitro. Journal of neurophysiology 94:2987-2992.

Jahromi SS, Pelletier MR, McDonald PJ, Khosravani H, Carlen PL (2000) Antiepileptic efficacy of topiramate: assessment in two in vitro seizure models. Brain research 872:20-28.

Jefferys JG (1981) Influence of electric fields on the excitability of granule cells in guinea-pig hippocampal slices. The Journal of physiology 319:143-152.

Josephson CB, Dykeman J, Fiest KM, Liu X, Sadler RM, Jette N, Wiebe S (2013) Systematic review and meta-analysis of standard vs selective temporal lobe epilepsy surgery. Neurology 80:1669-1676.

Kang EE, Zalay OC, Cotic M, Carlen PL, Bardakjian BL (2010) Transformation of neuronal modes associated with low-Mg2+/high-K+ conditions in an in vitro model of epilepsy. Journal of biological physics 36:95-107.

Kano T, Inaba Y, D'Antuono M, Biagini G, Levesque M, Avoli M (2015) Blockade of in vitro ictogenesis by low-frequency stimulation coincides with increased epileptiform response latency. Journal of neurophysiology 114:21-28.

Kinoshita M, Ikeda A, Begum T, Yamamoto J, Hitomi T, Shibasaki H (2005) Low-frequency repetitive transcranial magnetic stimulation for seizure suppression in patients with extratemporal lobe epilepsy-a pilot study. Seizure 14:387-392.

Kistsen V, Evstigneev V, Dubovik B, Ulashchik V (2016) The Effects of Repetitive Transcranial Magnetic Stimulation on Picrotoxin-Induced Convulsions in Mice. Adv Clin Exp Med 25:317-325.

Koivuniemi A, Wilks SJ, Woolley AJ, Otto KJ (2011) Multimodal, longitudinal assessment of intracortical microstimulation. Progress in brain research 194:131-144.

Komaki A, Khalili A, Salehi I, Shahidi S, Sarihi A (2014) Effects of exposure to an extremely low frequency electromagnetic field on hippocampal long-term potentiation in rat. Brain research 1564:1-8.

Konnerth A, Heinemann U, Yaari Y (1986) Nonsynaptic epileptogenesis in the mammalian hippocampus in vitro. I. Development of seizurelike activity in low extracellular calcium. Journal of neurophysiology 56:409-423. 
Koubeissi MZ, Kahriman E, Syed TU, Miller J, Durand DM (2013) Low-frequency electrical stimulation of a fiber tract in temporal lobe epilepsy. Annals of neurology 74:223-231.

Kwan P, Brodie MJ (2000) Early identification of refractory epilepsy. N Engl J Med 342:314-319.

Laxer KD, Trinka E, Hirsch L, Cendes F, Langfitt J, Delanty N, Resnick T, Benbadis SR (2014) The consequences of refractory epilepsy and its treatment. Epilepsy \& behavior : E\&B 37:59-70.

Ledri M, Madsen MG, Nikitidou L, Kirik D, Kokaia M (2014) Global optogenetic activation of inhibitory interneurons during epileptiform activity. The Journal of neuroscience : the official journal of the Society for Neuroscience 34:3364-3377.

Lee SW, Fallegger F, Casse BD, Fried SI (2016) Implantable microcoils for intracortical magnetic stimulation. Sci Adv 2:e1600889.

Lee SW, Fried SI (2014) The response of L5 pyramidal neurons of the PFC to magnetic stimulation from a micro-coil. Conference proceedings: Annual International Conference of the IEEE Engineering in Medicine and Biology Society IEEE Engineering in Medicine and Biology Society Annual Conference 2014:6125-6128.

Lian J, Bikson M, Sciortino C, Stacey WC, Durand DM (2003) Local suppression of epileptiform activity by electrical stimulation in rat hippocampus in vitro. The Journal of physiology 547:427-434.

Liu A, Pang T, Herman S, Pascual-Leone A, Rotenberg A (2013) Transcranial magnetic stimulation for refractory focal status epilepticus in the intensive care unit. Seizure 22:893-896.

Mann-Metzer P, Yarom Y (2000) Electrotonic coupling synchronizes interneuron activity in the cerebellar cortex. Progress in brain research 124:115-122.

Menkes DL, Gruenthal M (2000) Slow-frequency repetitive transcranial magnetic stimulation in a patient with focal cortical dysplasia. Epilepsia 41:240-242.

Mirski MA, Rossell LA, Terry JB, Fisher RS (1997) Anticonvulsant effect of anterior thalamic high frequency electrical stimulation in the rat. Epilepsy research 28:89-100.

Muller PA, Dhamne SC, Vahabzadeh-Hagh AM, Pascual-Leone A, Jensen FE, Rotenberg A (2014) Suppression of motor cortical excitability in anesthetized rats by low frequency repetitive transcranial magnetic stimulation. PLoS One 9:e91065.

Nanobashvili Z, Chachua T, Nanobashvili A, Bilanishvili I, Lindvall O, Kokaia Z (2003) Suppression of limbic motor seizures by electrical stimulation in thalamic reticular nucleus. Experimental neurology 181:224-230.

Orlowski D, Michalis A, Glud AN, Korshoj AR, Fitting LM, Mikkelsen TW, Mercanzini A, Jordan A, Dransart A, Sorensen JCH (2017) Brain Tissue Reaction to Deep Brain Stimulation-A Longitudinal Study of DBS in the Goettingen Minipig. Neuromodulation : journal of the International Neuromodulation Society 20:417-423.

Pantoja-Jimenez CR, Magdaleno-Madrigal VM, Almazan-Alvarado S, Fernandez-Mas R (2014) Antiepileptogenic effect of high-frequency stimulation in the thalamic reticular nucleus on PTZinduced seizures. Brain stimulation 7:587-594.

Polikov VS, Tresco PA, Reichert WM (2005) Response of brain tissue to chronically implanted neural electrodes. Journal of neuroscience methods 148:1-18.

Rashid S, Pho G, Czigler M, Werz MA, Durand DM (2012) Low frequency stimulation of ventral hippocampal commissures reduces seizures in a rat model of chronic temporal lobe epilepsy. Epilepsia 53:147-156.

Rav-Acha M, Sagiv N, Segev I, Bergman H, Yarom Y (2005) Dynamic and spatial features of the inhibitory pallidal GABAergic synapses. Neuroscience 135:791-802.

Richardson TL, O'Reilly CN (1995) Epileptiform activity in the dentate gyrus during low-calcium perfusion and exposure to transient electric fields. Journal of neurophysiology 74:388-399. 
Rosenbaum R, Zimnik A, Zheng F, Turner RS, Alzheimer C, Doiron B, Rubin JE (2014) Axonal and synaptic failure suppress the transfer of firing rate oscillations, synchrony and information during high frequency deep brain stimulation. Neurobiology of disease 62:86-99.

Rossi S, Hallett M, Rossini PM, Pascual-Leone A, Safety of TMSCG (2009) Safety, ethical considerations, and application guidelines for the use of transcranial magnetic stimulation in clinical practice and research. Clinical neurophysiology : official journal of the International Federation of Clinical Neurophysiology 120:2008-2039.

Saillet S, Langlois M, Feddersen B, Minotti L, Vercueil L, Chabardes S, David O, Depaulis A, Deransart C, Kahane $P$ (2009) Manipulating the epileptic brain using stimulation: a review of experimental and clinical studies. Epileptic disorders : international epilepsy journal with videotape 11:100112.

Sandyk R, Anninos PA (1992) Magnetic fields alter the circadian periodicity of seizures. Int J Neurosci 63:265-274.

Saxena T, Karumbaiah L, Gaupp EA, Patkar R, Patil K, Betancur M, Stanley GB, Bellamkonda RV (2013) The impact of chronic blood-brain barrier breach on intracortical electrode function. Biomaterials 34:4703-4713.

Sillay KA, Rutecki P, Cicora K, Worrell G, Drazkowski J, Shih JJ, Sharan AD, Morrell MJ, Williams J, Wingeier B (2013) Long-term measurement of impedance in chronically implanted depth and subdural electrodes during responsive neurostimulation in humans. Brain stimulation 6:718-726.

Smart O, Rolston JD, Epstein CM, Gross RE (2013) Hippocampal seizure-onset laterality can change over long timescales: A same-patient observation over 500 days. Epilepsy \& behavior case reports 1:56-61.

Snow RW, Dudek FE (1984) Electrical fields directly contribute to action potential synchronization during convulsant-induced epileptiform bursts. Brain research 323:114-118.

Sun W, Mao W, Meng X, Wang D, Qiao L, Tao W, Li L, Jia X, Han C, Fu M, Tong X, Wu X, Wang Y (2012) Low-frequency repetitive transcranial magnetic stimulation for the treatment of refractory partial epilepsy: a controlled clinical study. Epilepsia 53:1782-1789.

Sung JH, Jeong JH, Kim JS, Choi TS, Park JH, Kang HY, Kim YS, Kim DS, Sohn UD (2003) The influences of extremely low frequency magnetic fields on drug-induced convulsion in mouse. Arch Pharm Res 26:487-492.

Theodore WH, Fisher RS (2004) Brain stimulation for epilepsy. The Lancet Neurology 3:111-118.

Thomas GP, Jobst BC (2015) Critical review of the responsive neurostimulator system for epilepsy. Medical devices 8:405-411.

Tokay T, Holl N, Kirschstein T, Zschorlich V, Kohling R (2009) High-frequency magnetic stimulation induces long-term potentiation in rat hippocampal slices. Neuroscience letters 461:150-154.

Toprani S, Durand DM (2013) Long-lasting hyperpolarization underlies seizure reduction by low frequency deep brain electrical stimulation. The Journal of physiology 591:5765-5790.

Velasco AL, Velasco F, Velasco M, Trejo D, Castro G, Carrillo-Ruiz JD (2007) Electrical stimulation of the hippocampal epileptic foci for seizure control: a double-blind, long-term follow-up study. Epilepsia 48:1895-1903.

Velasco M, Velasco F, Velasco AL, Jimenez F, Brito F, Marquez I (2000) Acute and chronic electrical stimulation of the centromedian thalamic nucleus: modulation of reticulo-cortical systems and predictor factors for generalized seizure control. Archives of medical research 31:304-315.

Yamamoto J, Ikeda A, Kinoshita M, Matsumoto R, Satow T, Takeshita K, Matsuhashi M, Mikuni N, Miyamoto S, Hashimoto N, Shibasaki H (2006) Low-frequency electric cortical stimulation decreases interictal and ictal activity in human epilepsy. Seizure 15:520-527.

Ye H, Kaszuba S (2019) Neuromodulation with electromagnetic stimulation for seizure suppression: From electrode to magnetic coil. IBRO reports 7:26-33. 
Ye H, Morton DW, Chiel HJ (2006a) Neuromechanics of coordination during swallowing in Aplysia californica. The Journal of neuroscience : the official journal of the Society for Neuroscience 26:1470-1485.

Ye H, Morton DW, Chiel HJ (2006b) Neuromechanics of multifunctionality during rejection in Aplysia californica. The Journal of neuroscience : the official journal of the Society for Neuroscience 26:10743-10755.

Ye H, Steiger A (2015) Neuron matters: electric activation of neuronal tissue is dependent on the interaction between the neuron and the electric field. Journal of neuroengineering and rehabilitation 12 .

Zhang ZJ, Koifman J, Shin DS, Ye H, Florez CM, Zhang L, Valiante TA, Carlen PL (2012) Transition to seizure: ictal discharge is preceded by exhausted presynaptic GABA release in the hippocampal CA3 region. The Journal of neuroscience : the official journal of the Society for Neuroscience 32:2499-2512. 
A

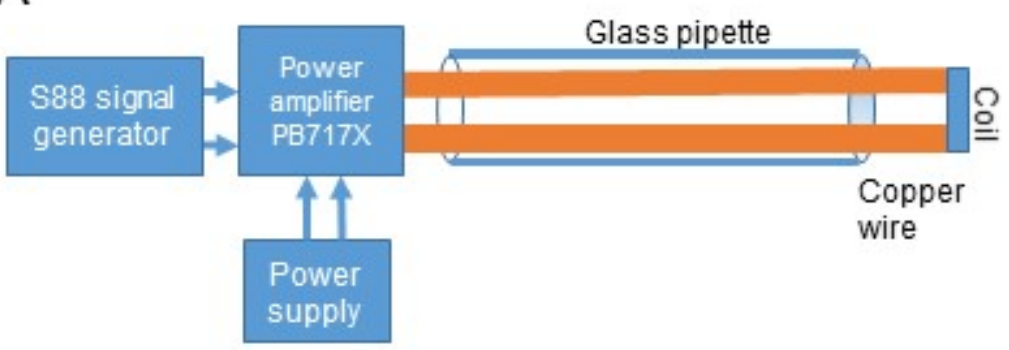

B

Recording glass electrode

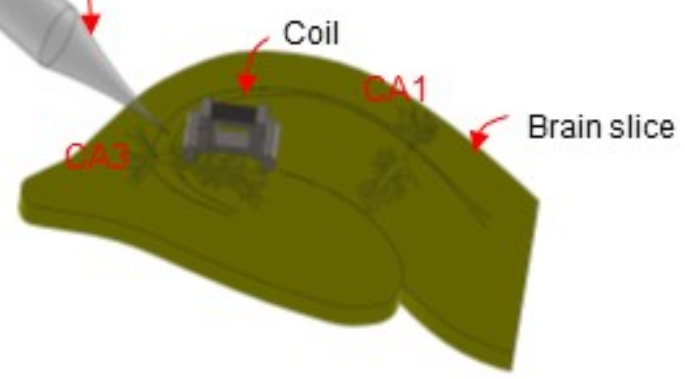

C

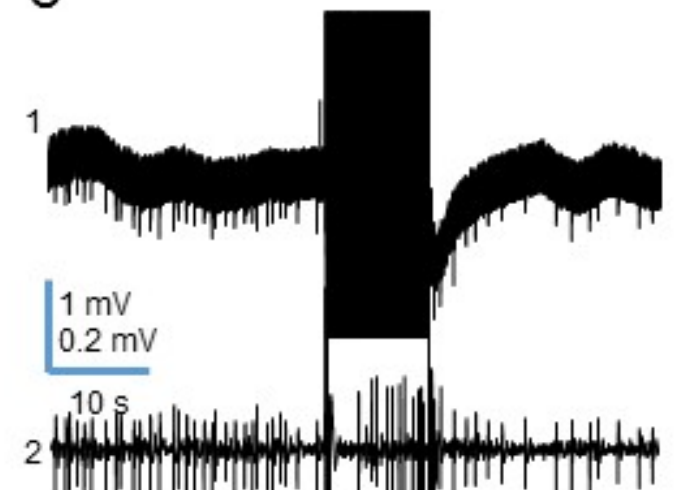

2 (n)

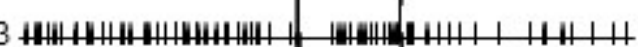

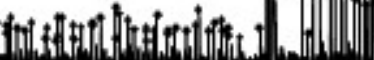

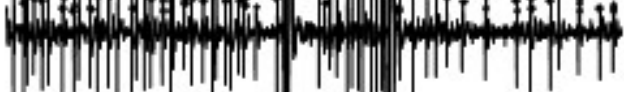




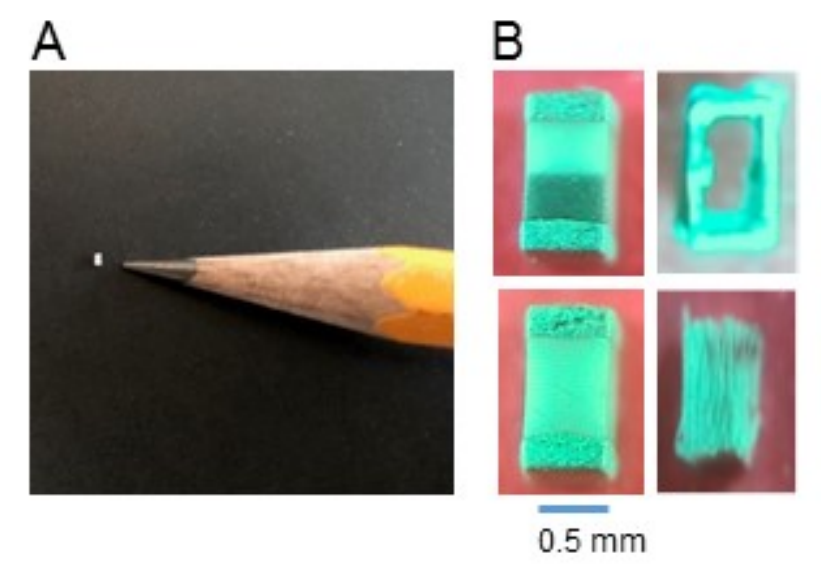


<smiles>O</smiles> 

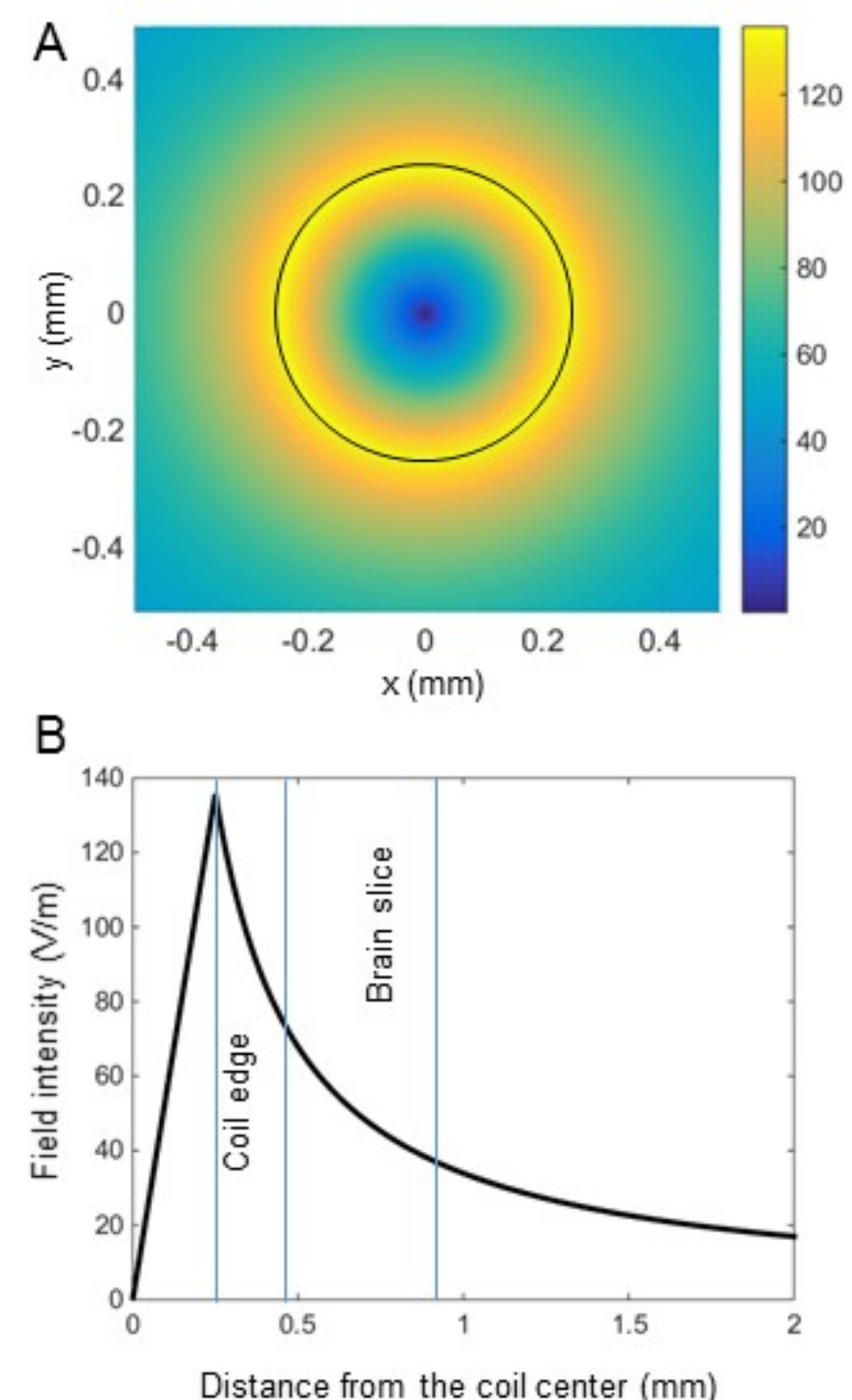
A

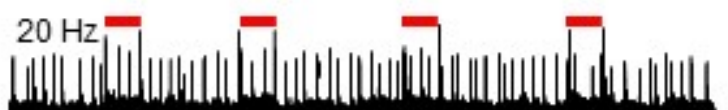
HIII|

C $100 \mathrm{~Hz}$

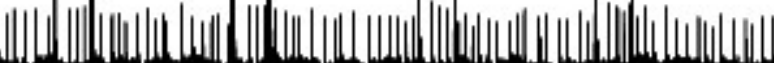

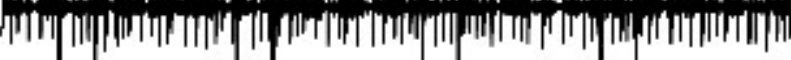

E

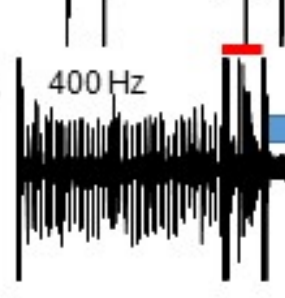

$\mathrm{F}$

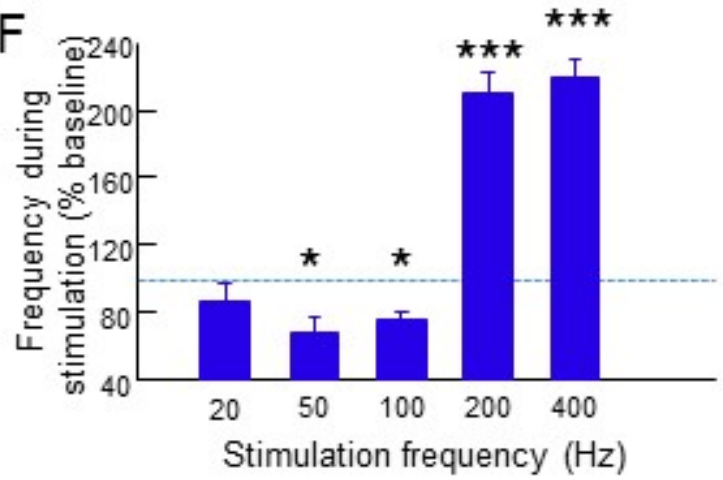

B

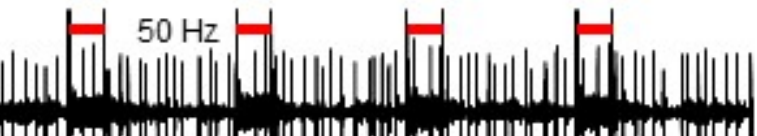

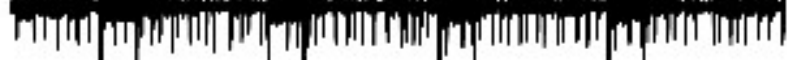

$200 \mathrm{~Hz}=1$

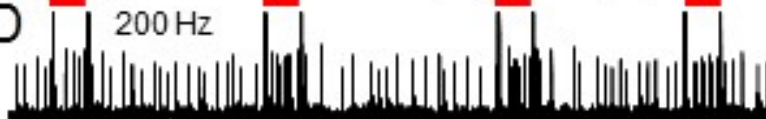

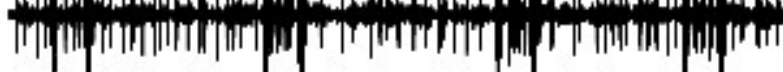
1 - 1 | $\overline{\mid l}$ Complete suppression 17 $\mid$ |illik

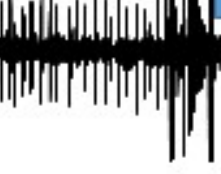

G

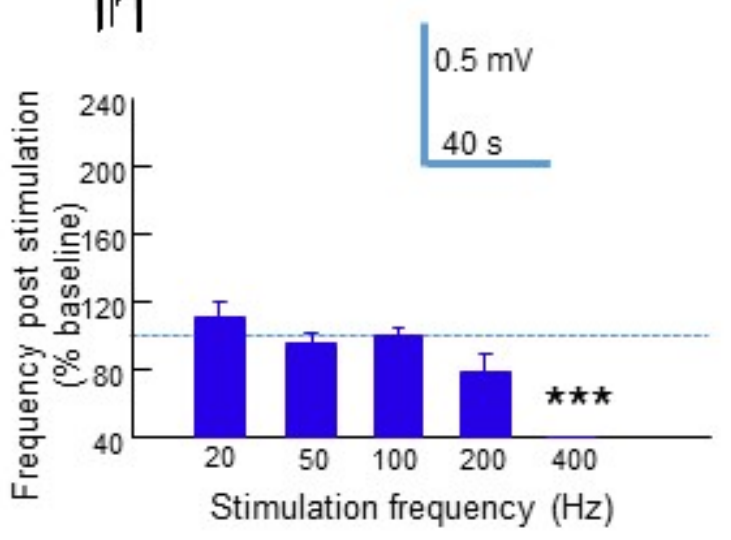




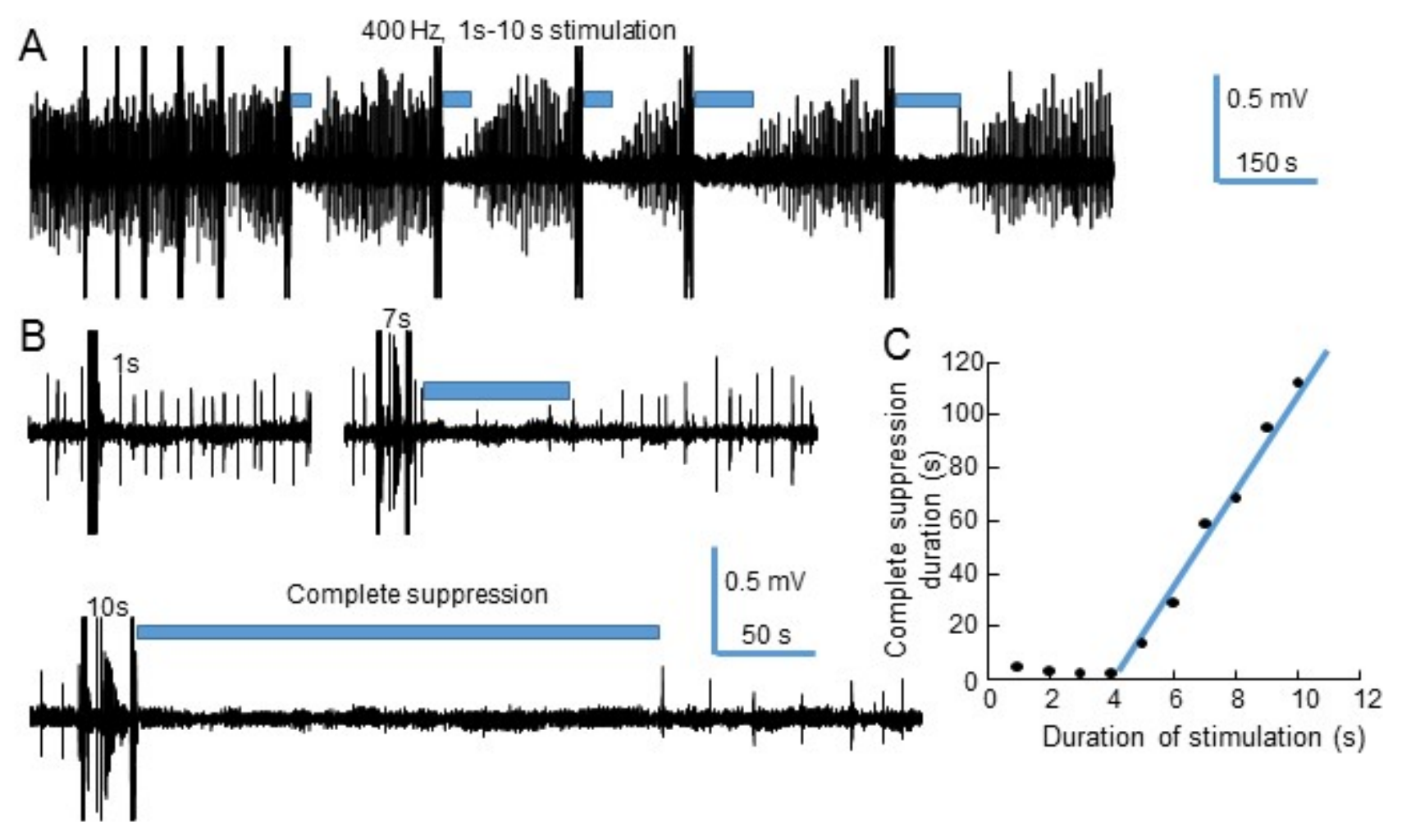




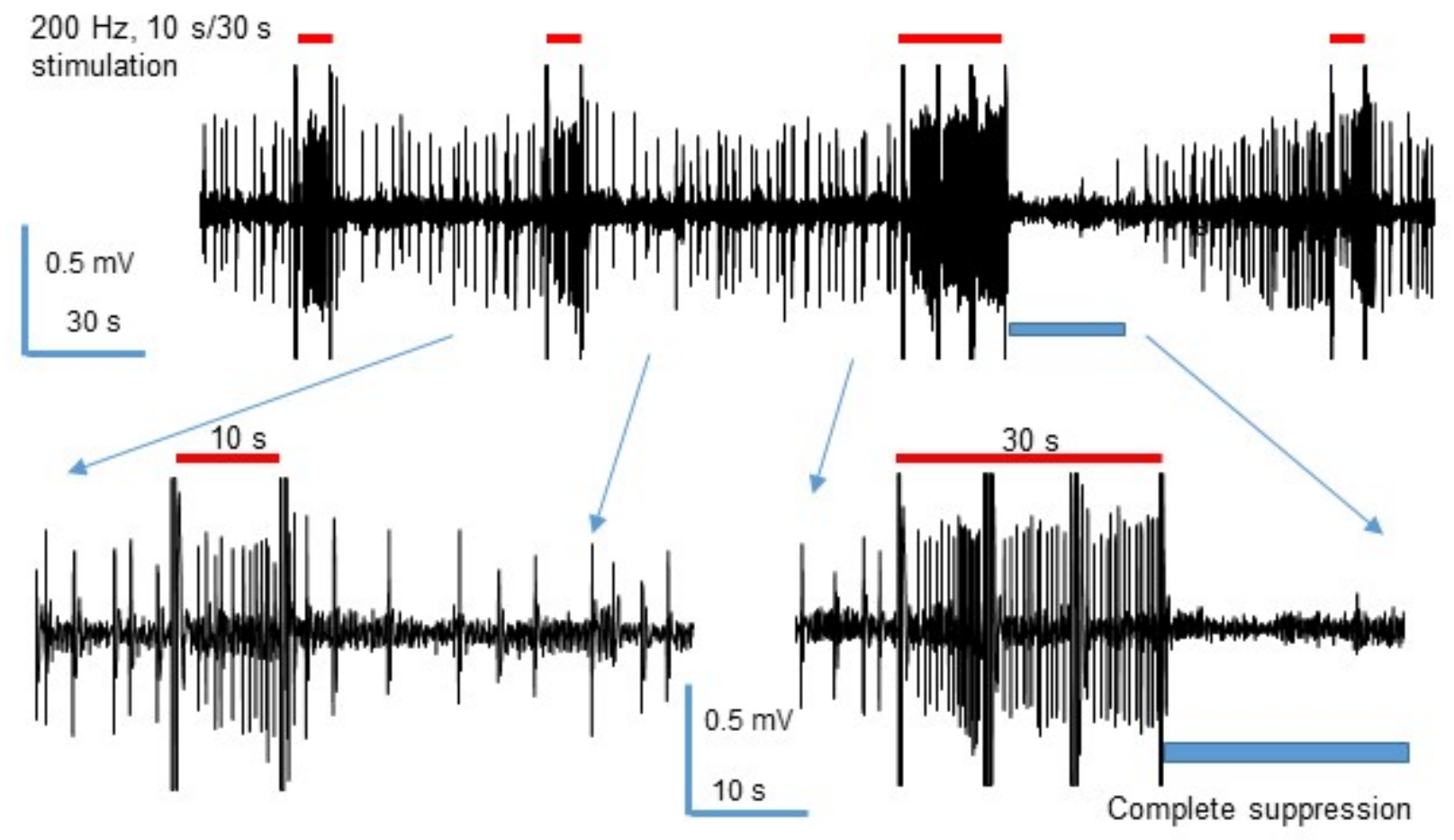


A

Recording glass electrode

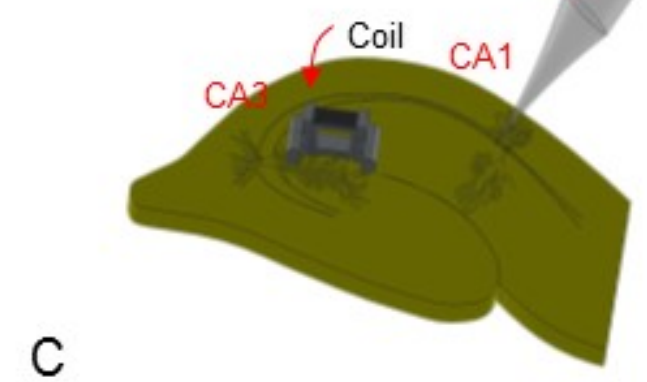

C

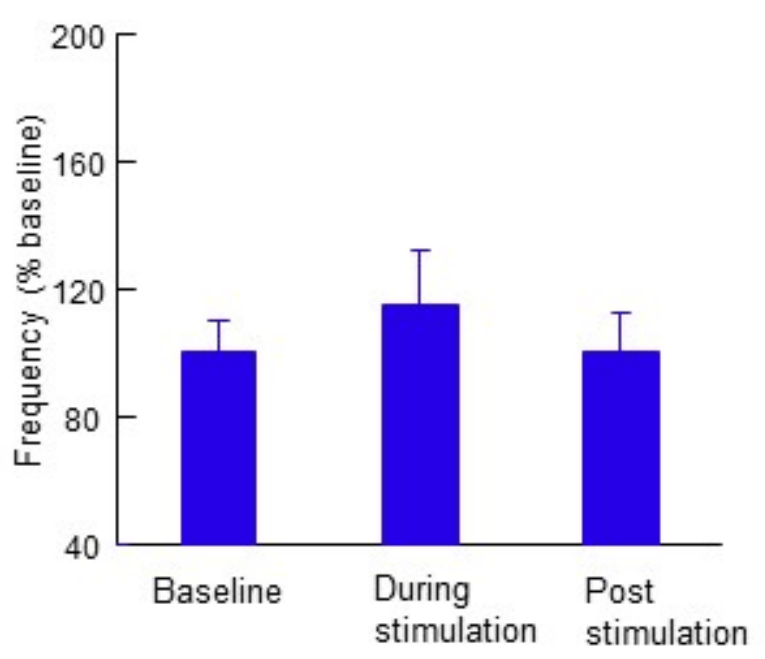

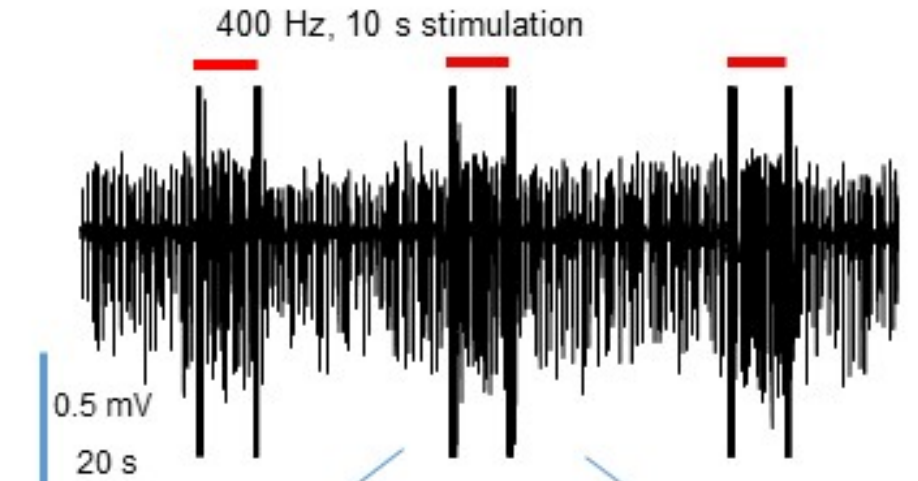

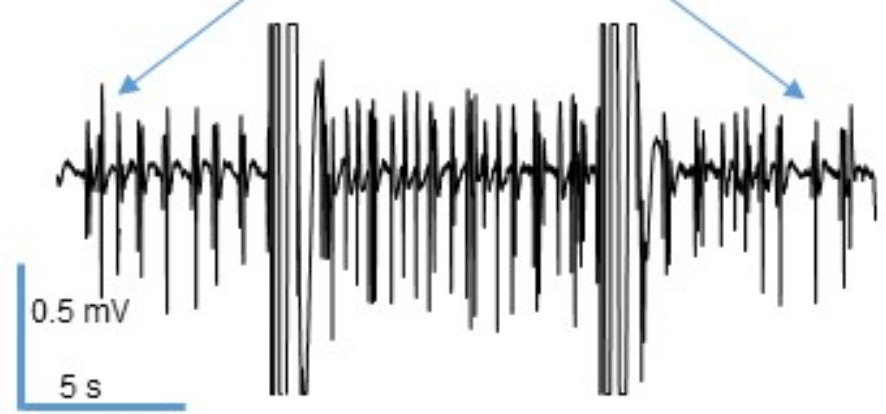



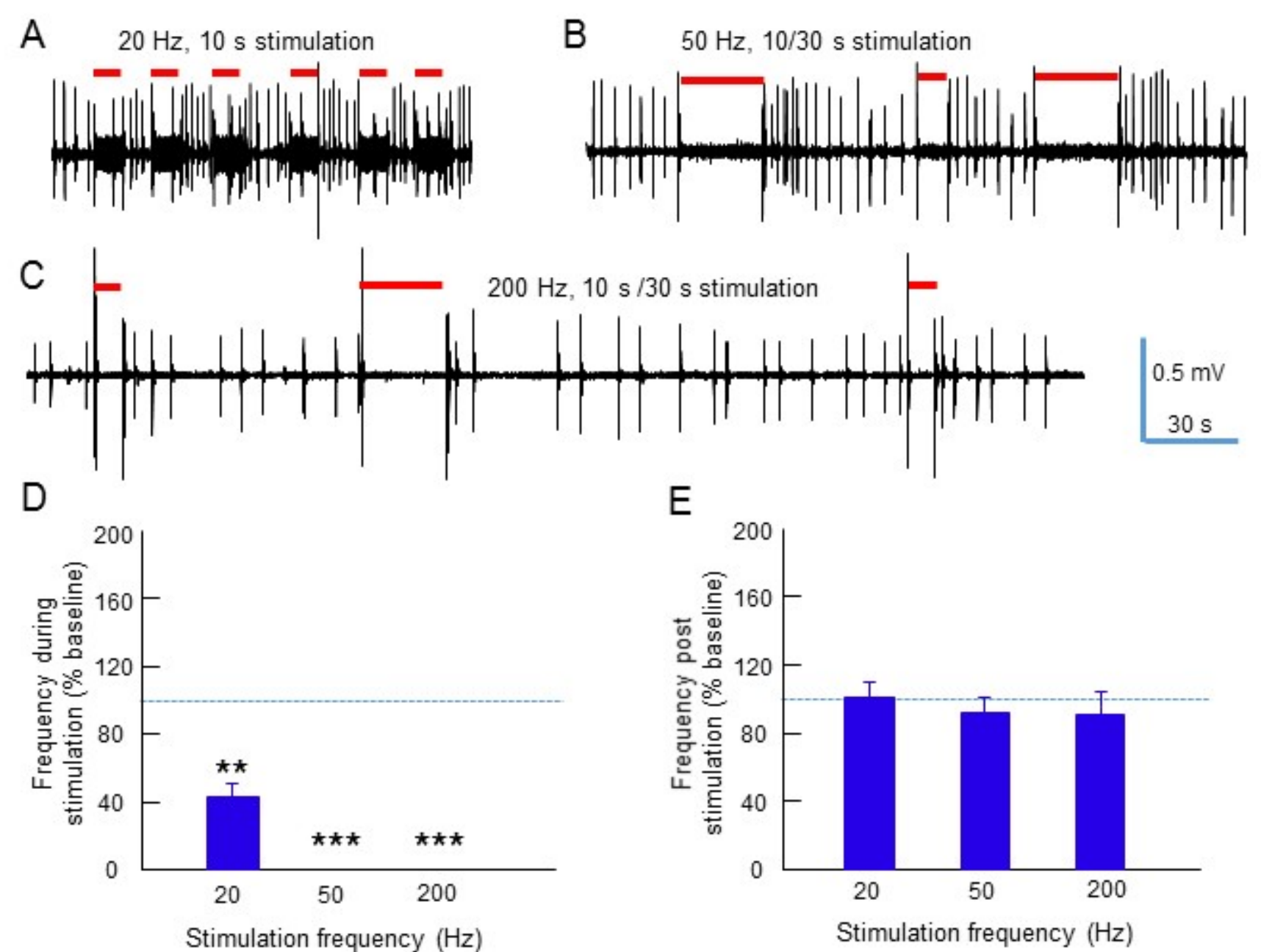